\title{
Sociodemographic characteristics and disability pensions of frequent attenders in occupational health primary care - a follow-up study in Finland
}

Tiia Reho ${ }^{1,2^{*}}$ (D, Salla Atkins ${ }^{3,4}$, Mikko Korhonen ${ }^{1}$, Anna Siukola', Markku Sumanen', Mervi Viljamaa², Jukka Uitti ${ }^{1,5,6}$ and Riitta Sauni ${ }^{1}$

\begin{abstract}
Background: Work disability is a complex issue that requires preventive efforts from healthcare systems and individuals, and that too often results in disability pensions (DP). While many studies have attempted to characterize risk factors of work disability, many showing for example a link between socioeconomic positions, working conditions and frequent attendance to $\mathrm{OH}$ primary care it is not known if frequent attendance is associated with DP despite the sociodemographic factors. This study aims to address this gap and examine the association between frequent attendance to $\mathrm{OH}$ primary care and DP, when adjusted by sociodemographic factors.

Methods: This study combines routine medical record data of an occupational health service provider with comprehensive national registers. Medical record data were used to define groups of frequent attenders to $\mathrm{OH}$ primary care (FA) (1-year-FA, 2-year-FA, persistent-FA and non-FA) from 2014 to 2016. The sociodemographic factors (including i.e. educational level, occupational class, unemployment periods) were derived from Statistic Finland and DP decisions were derived from Finnish Centre for Pensions. Association of frequent attendance to $\mathrm{OH}$ primary care with DP decisions were analyzed and adjusted by sociodemographic factors.

Results: In total, 66,381 patients were included. Basic and intermediate education along with manual and lower non-manual work predicted frequent attendance to OH primary care. Unemployment in 2013 did not predict frequent attendance to $\mathrm{OH}$ primary care. Frequent attendance to $\mathrm{OH}$ primary care was associated with DP within next two years, even when adjusted for sociodemographic factors. The association of frequent attendance to $\mathrm{OH}$ primary care with DP grew stronger as high service use persisted over time.

Conclusions: Frequent attendance to OH primary care is associated with DP risk in the near future despite the underlying sociodemographic differences. Patients using $\mathrm{OH}$ primary care services extensively should be identified and rehabilitative needs and measures necessary to continue in the work force should be explored. Sociodemographic issues that co-exist should be explored and considered when planning interventions.
\end{abstract}

\footnotetext{
* Correspondence: tiia.reho@gmail.com

${ }^{1}$ Tampere University, Faculty of Medicine and Health Technology, Tampere,

Finland

2Pihlajalinna Työterveys, Tampere, Finland

Full list of author information is available at the end of the article
}

(c) The Author(s). 2021 Open Access This article is licensed under a Creative Commons Attribution 4.0 International License, which permits use, sharing, adaptation, distribution and reproduction in any medium or format, as long as you give appropriate credit to the original author(s) and the source, provide a link to the Creative Commons licence, and indicate if changes were made. The images or other third party material in this article are included in the article's Creative Commons licence, unless indicated otherwise in a credit line to the material. If material is not included in the article's Creative Commons licence and your intended use is not permitted by statutory regulation or exceeds the permitted use, you will need to obtain permission directly from the copyright holder. To view a copy of this licence, visit http://creativecommons.org/licenses/by/4.0/ The Creative Commons Public Domain Dedication waiver (http://creativecommons.org/publicdomain/zero/1.0/) applies to the data made available in this article, unless otherwise stated in a credit line to the data. 
Keywords: Frequent attender, Disability pension, Occupational health service, Health inequalities, Primary care, Healthcare utilization, Working age

\section{Background}

One tenth of patients conduct more than a third of primary healthcare visits and create an even larger proportion of costs [1-3]. This tenth is often termed frequent attenders to $\mathrm{OH}$ primary care (FAs), and they can be found in most healthcare systems creating a similar demand across settings [4-6]. The FA definition is not a stable one; some patients are FA only temporarily for a year, but others continue frequent visits for several years - the latter often being described as persistent FAs $[1,7,8]$. It is still unclear why some patients continue high service use while others cease and if these patients differ from each other.

FAs share some common characteristics including multimorbidity, worse self-perceived health and quality of life [3, 9-12]. In addition, unemployment has been linked to frequent attendance to $\mathrm{OH}$ primary care in the GP setting $[13,14]$ and low socioeconomic status has been linked to frequent service use and sickness absences [15]. Previous studies have established that frequent attendance is associated with a higher risk of work disability, also after frequent visits have ceased [16, 17]. However, as these studies have not controlled for sociodemographic factors, the question can be raised about the veracity of the frequent attendance to $\mathrm{OH}$ primary care as an independently associated variable. Sociodemographic factors, or the social determinants of health including low education levels and socioeconomic status, are established as risk factors for work disability [18-20]. Although the criteria for DP are medical, social determinants of health, including gender, education, income or poverty and employment act as background variables impacting on the occurrence and severity of disability [21]. Considering these factors and their relation to frequent attendance allows a more comprehensive understanding of work disability, and possibly, earlier measures to improve work ability.

Finnish occupational health services (OHS) is a unique environment to study the working population. The voluntary primary care provided by employers to employees covers up to $90 \%$ of the working population and it is often used as the sole primary care provider of the employees despite functioning parallel to private and public primary care $[22,23]$. Occupational health $(\mathrm{OH})$ primary care includes curative care, such as visits to physician and nurse, and through consultation also psychologist, physiotherapist and often medical specialists. However, the services are linked to employment relationship, and disruptions in employment will affect service use patterns. Although $\mathrm{OH}$ primary care as such does not exist elsewhere, in most countries the working population is treated by the GPs and understanding the characteristics of the working population FAs is necessary in these settings, too. There is minimal information on FAs among the working aged or the working population.

The working population is different from the general practice population as they have been fit enough to enter and stay in the work force [24]. However, the working population is heterogeneous in terms of illnesses and social and economic conditions [25, 26]. Frequent attendance exists in $\mathrm{OH}$ primary care similarly to other healthcare settings [4], but its predictors in OHS may be different when compared with the general population. The service demand and economic burden created by the FAs in $\mathrm{OH}$ primary care - a tenth makes over a third of the visits [4] - is notable but even more pressing is their association with work disability. Disability retirement is a loss for the workplace, the individual and the society both in economic and humane terms.

OHS in Finland aims to prevent work disability and withdrawal from the workforce in collaboration with employers and employees. To design purposeful interventions to those workers that are at risk of work disability - such as FAs - we need a wider conception of characteristics linked to FAs in $\mathrm{OH}$ primary care. With enough understanding on socioeconomic conditions that are linked to frequent attendance to $\mathrm{OH}$ primary care, we can identify the right groups for interventions but also plan the interventions purposefully. We also need further information on the independent risks associated with frequent attendance to $\mathrm{OH}$ primary care and work disability.

This study aimed to investigate the sociodemographic factors of different FA groups in $\mathrm{OH}$ primary care and investigate the association of frequent attendance to $\mathrm{OH}$ primary care with DPs.

\section{Methods}

\section{Study setting and design}

The Finnish OHS contain two structures: the mandatory preventive part and the voluntary primary care part, which are arranged by the same service provider. $\mathrm{OH}$ primary care are funded in most part by the employer, but when used it is free of charge for the employee. $\mathrm{OH}$ primary care functions alongside public and private primary care but is often used as the sole primary care 
provider [23]. This study is a retrospective follow-up study using routine medical record data from a large private $\mathrm{OHS}$ provider Pihlajalinna Työterveys, which at the time of the study included $40 \mathrm{OH}$ units across Finland. A follow-up design was chosen to analyze factors associated with frequent attendance to $\mathrm{OH}$ primary care and DP. Pihlajalinna Työterveys' clients represent the working population of Finland fairly well including companies from a wide range of industries and rural as well as urban areas.

While medical records contain the necessary information on patients' illnesses and their treatment, they have little information on sociodemographic factors, such as occupational class or education. These are available from national registers controlled by Statistics Finland. This study combines routine medical record data that is used to identify FAs and combines it with sociodemographic data from Statistics Finland and further with disability pension data from Finnish Centre for Pensions (FCP).

In Finland, a DP may be granted when work ability is decreased for longer than a year based on an illness. When work ability is decreased by $2 / 5$ a partial DP is granted and when it is decreased by $3 / 5$ a full DP may be granted. Fixed-term solutions (partial or full-time) are granted when rehabilitation and return to work later is expected. Permanent full DP leads to withdrawal from the workforce. DPs are funded by a mandatory insurance paid by employees and employers. In this study we use the Finnish categorization for DPs as outcome variables: 1) Permanent full-time DP, 2) Permanent partial DP, 3) Fixed-term DP, 4) Fixed-term partial DP.

\section{Data collection}

$\mathrm{OH}$ primary care data contained information on visits to different professionals (2014-2016) and were used to determine frequent attendance to $\mathrm{OH}$ primary care. The data were sent by Pihlajalinna to Statistics Finland, which pseudonymized the data and combined it with sociodemographic data from the FOLK-database [27]. The DP decisions were derived from Finnish Centre for Pensions (FCP), which were also sent to Statistic Finland and combined with the pseudonymized data. Tampere University processed the pseudonymized data in the information safe FIONA-environment provided by Statistics Finland.

Our initial data comprised 78,507 patients. The study material was limited to employees aged $18-68$ years who had visited the $\mathrm{OH}$ primary care face-to-face at least once during the study years. Only illness related visits conducted face-to-face were included, and mandatory health check-ups were excluded. We excluded patients of whom there was no record in 2015 since sociodemographic data were drawn from $2015(n=445)$. After these exclusions our study comprised 66,386 patients.

\section{Statistical analysis}

FAs were defined as top decile of healthcare attenders in $\mathrm{OH}$ primary care during 2014-2016. Details on defining FA-groups can be found described in a previous study, but a minimum of eight face-to-face visits in a year was held as a limit for becoming a FA [26]. Those patients that were in the top decile of attenders in one of the study years $(2014,2015$ or 2016) were named 1-year-FA $(1 \mathrm{yFA})$. The patients that were in the top decile in any two study years were named 2-year-FA (2yFA). Those patients that were in the top decile in all three study years were considered persistent frequent attenders (pFA). Patients that were never in the top decile were considered as a reference group, non-frequent attenders (non-FA). The cohort used in this study is dynamic and patients could be lost to follow-up due to employment termination. A flow diagram of patient categorization and exclusions can be found in a previous paper [26].

The sociodemographic variables were derived from the Statistics Finland FOLK-database. In the descriptive part we examined occupational class divided into manual (e.g. cleaners, cooks, mechanics), lower non-manual (e.g. sales assistants, nurses), upper non-manual (e.g. managers, engineers, teachers), entrepreneur combined with farmers and lastly others $[28,29]$. We also examined educational level (basic < 10 years, intermediate 10-12 years, high $>13$ years) [28] and living alone [28]. All these factors were drawn from 2015 which was in the middle of our study period to describe the sociodemographic characteristics of $\mathrm{OH}$ primary care FAs. When examining whether sociodemographic factors predict frequent attendance to $\mathrm{OH}$ primary care, we used occupational class, educational level, unemployment and living alone in 2013, which was before the chosen FAperiod. When examining whether frequent attendance to $\mathrm{OH}$ primary care was associated with disability pensions despite sociodemographic factors, we used occupational class, educational level, living alone, area of living (divided into urban, semi-urban, rural) [22], unemployment and disposable family income [28] from 2014 in adjusting the models. Matching with social determinants of health, we used occupational class to estimate employment; education for education; and living alone and area of living for social support and neighborhood factors, unemployment and disposable family income as indicators of income or poverty. The endpoint was disability pension decision (permanent full-time DP, permanent partial DP, fixed-term DP, fixed-term partial DP) in 2017-2018.

The data were analysed using R-software. In all analyses $P$ values less than 0.05 were considered statistically significant. We used multinomial logistic regression with occupational class, educational level and unemployment from 2013 compared with frequent attendance to $\mathrm{OH}$ 
primary care in 2014-2016 to study if unemployment, educational level or occupational class predict frequent attendance to $\mathrm{OH}$ primary care. These analyses were adjusted with age and sex. In the analysis examining the predictive power of frequent attendance to $\mathrm{OH}$ primary care for DP decisions, the logistic regression analyses were adjusted for age, sex, occupational class, educational level, living alone, area of living, unemployment and disposable family income from 2015 . We also examined if there were differences in proportions of different FA-groups being unemployed in years 2013 and 2017.

\section{Results}

The study population after exclusions comprised 66,386 patients (2014-2016). When divided into four categories $592(0.9 \%)$ patients were pFAs, 1602 (2.4\%) 2yFAs, 6519 (9.8\%) 1yFAs and 57,673 (86.9\%) non-FAs.

Descriptive data are shown in Table 1 . The pFAs often have an intermediate education level and belong to manual workers. Living alone also appears to be more common among FAs. Approximately $90 \%$ of pFAs were employed in 2013 and 2017, the respective proportions for non-FA were $86 \%$ in 2013 and $87 \%$ in 2017. Only $6 \%$ of pFAs and $10 \%$ of non-FAs had been unemployed for 45 days or more in 2013, while the unemployment rate in 2017 was $8 \%$ of pFAs and $10 \%$ of non-FAs (data not shown).

In the two years following the FA-period, the pFA group received proportionally most DP decisions of any kind $(1.9 \%$ of pFA, $1.6 \%$ of $2 \mathrm{yFA}, 1.1 \%$ of $1 \mathrm{yFA}$ and $0.3 \%$ of non-FA) (Table 2). The 1yFA and 2yFA groups differed only slightly so that $2 \mathrm{yFAs}$ had proportionally more full-time pensions than the others.

Being a manual worker in 2013 was associated with frequent attendance to $\mathrm{OH}$ primary care in the following years for both genders, when compared to upper nonmanual workers (Table 3). Specifically, lower nonmanual work was associated with being 1yFA- and 2yFA for both genders but with pFA for only females. Concurrently, basic and intermediate education were associated with frequent attendance to $\mathrm{OH}$ primary care for males, but for females only intermediate education was significant. Entrepreneurship on the other hand was associated with a lower likelihood of being FA for both genders. Being unemployed in 2013 was not linked to frequent attendance to $\mathrm{OH}$ primary care in the following years but, on the contrary, it was linked to a lower likelihood to being in the 2yFA in females but not in males. Living alone was linked with being pFA for both sexes.

When studying the individual predictive power of frequent attendance to $\mathrm{OH}$ primary care being FA was predictive of permanent full-time DP and any DP, including also short-term solutions for both sexes (Table 4). This association grew stronger as frequent attendance to $\mathrm{OH}$
Table 1 Distribution of sociodemographic factors in different FA groups in $2015(N=66,386)$

\begin{tabular}{|c|c|c|c|c|c|c|c|c|}
\hline & \multicolumn{2}{|c|}{$\begin{array}{l}\text { non-FA } \\
n=57,673\end{array}$} & \multicolumn{2}{|c|}{$\begin{array}{l}1 y F A \\
n=6519\end{array}$} & \multicolumn{2}{|c|}{$\begin{array}{l}2 y F A \\
n=1602 \\
\end{array}$} & \multicolumn{2}{|c|}{$\begin{array}{l}\text { PFA } \\
n=592\end{array}$} \\
\hline & $\%$ & $n$ & $\%$ & 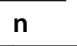 & $\%$ & $n$ & $\%$ & $n$ \\
\hline Male & 57 & 32,915 & 50 & 3265 & 47 & 753 & 44 & 262 \\
\hline Female & 43 & 24,758 & 50 & 3254 & 53 & 849 & 56 & 330 \\
\hline $18-34$ & 33 & 18,973 & 25 & 1609 & 19 & 307 & 19 & 111 \\
\hline $35-44$ & 23 & 13,499 & 24 & 1588 & 25 & 398 & 23 & 139 \\
\hline $45-54$ & 25 & 14,257 & 29 & 1880 & 30 & 480 & 32 & 191 \\
\hline $55-68$ & 19 & 10,944 & 22 & 1442 & 26 & 417 & 26 & 151 \\
\hline \multicolumn{9}{|l|}{ Occupational class } \\
\hline Manual & 31 & 17,753 & 41 & 2664 & 46 & 732 & 52 & 307 \\
\hline Lower non-manual & 31 & 17,766 & 36 & 2347 & 36 & 585 & 33 & 195 \\
\hline Upper non-manual & 19 & 11,014 & 14 & 918 & 12 & 190 & 11 & 63 \\
\hline Entrepreneurs & 4 & 2420 & 2 & 124 & 1 & 14 & $<1$ & - \\
\hline Others* & 15 & 8720 & 7 & 466 & 5 & 81 & 4 & 25 \\
\hline \multicolumn{9}{|l|}{ Educational level } \\
\hline Basic & 10 & 6040 & 10 & 681 & 10 & 157 & 11 & 65 \\
\hline Intermediate & 49 & 28,364 & 56 & 3643 & 58 & 929 & 62 & 369 \\
\hline High & 40 & 23,269 & 34 & 2195 & 32 & 516 & 27 & 158 \\
\hline \multicolumn{9}{|l|}{ Living alone } \\
\hline Alone & 19 & 10,884 & 20 & 1286 & 21 & 332 & 26 & 154 \\
\hline Not alone & 80 & 46,197 & 80 & 5180 & 78 & 1256 & 74 & 436 \\
\hline Missing & 1 & 592 & $<1$ & 53 & 1 & 14 & $<1$ & - \\
\hline
\end{tabular}

Frequent attendance to $\mathrm{OH}$ primary care was defined as the top decile of attenders (frequent attender 10\%, FA10)

$1 \mathrm{yFA}=$ Patients that were in the top decile of attenders in one of the study years $(2014,2015$ or 2016)

2yFA = Patients that were in the top decile in any two study years $(2014,2015$ or 2016)

pFA = Patients that were in the top decile in all three study years (2014, 2015 and 2016)

non-FA = Patients that were never in the top decile were considered as a reference group, non-frequent attenders

*Unemployed, students, pensioners, others, unknown

primary care persisted for two or more years. The associations differed slightly for male and female with $2 y F A s$, the association being stronger with females (OR for permanent full-time DP 7.96 (4.54-13.95) for females and $2.31(1.10-4.83)$ for males. Frequent attendance to $\mathrm{OH}$ primary care was predictive of DP even when adjusted for confounding socioeconomic factors.

\section{Discussion}

This study provides new understanding on frequent attendance to $\mathrm{OH}$ primary care and its associations with work disability. The finding that frequent attendance to $\mathrm{OH}$ primary care is associated with work disability despite sociodemographic factors, is novel. This is also the first study to describe the sociodemographic factors of FAs in $\mathrm{OH}$ primary care, representing the working population in Finland. 
Table 2 Proportions (\%) of disability pension decisions for different FA groups in 2017-2018

\begin{tabular}{|c|c|c|c|c|c|c|c|c|}
\hline & \multirow{2}{*}{$\begin{array}{l}\text { Permanent full-time DP 2017-2018 } \\
\%\end{array}$} & \multicolumn{3}{|c|}{$\begin{array}{l}\text { Permanent partial DP 2017- } \\
2018\end{array}$} & \multicolumn{2}{|c|}{$\begin{array}{l}\text { Fixed-term DP 2017- } \\
2018\end{array}$} & \multicolumn{2}{|c|}{$\begin{array}{l}\text { Fixed-term partial DP } \\
2017-2018\end{array}$} \\
\hline & & $n$ & $\%$ & $\mathbf{n}$ & $\%$ & $\mathbf{n}$ & $\%$ & $\mathbf{n}$ \\
\hline non-FA $(n=57,673)$ & 0.3 & 158 & 0.3 & 180 & 0.2 & 121 & 0.1 & 38 \\
\hline 1yFA $(n=6519)$ & 1.1 & 69 & 1.0 & 64 & 1.0 & 64 & 0.4 & 25 \\
\hline $2 y F A(n=1602)$ & 1.6 & 26 & 1.1 & 19 & 1.6 & 26 & 0.3 & 5 \\
\hline pFA $(n=592)$ & 1.9 & 11 & 1.5 & 9 & 1.9 & 11 & 0.8 & 5 \\
\hline
\end{tabular}

Frequent attendance to $\mathrm{OH}$ primary care was defined as the top decile of attenders (frequent attender 10\%, FA10)

$1 \mathrm{yFA}=$ Patients that were in the top decile of attenders in one of the study years $(2014,2015$ or 2016)

2yFA = Patients that were in the top decile in any two study years $(2014,2015$ or 2016)

pFA = Patients that were in the top decile in all three study years (2014, 2015 and 2016)

non-FA = Patients that were never in the top decile were considered as a reference group, non-frequent attenders

For the first time, in this study, we were also able to analyse the sociodemographic factors associated with frequent attendance to $\mathrm{OH}$ primary care in $\mathrm{OH}$ primary care. The finding that manual and lower non-manual workers were overrepresented in the FA group was expected. Social determinants of health, including employment conditions, gender, income, and education influence health status [30]. The relationship between the social determinants of health and health outcomes including morbidity and mortality is complex. In general, it could be thought that as a person lives in a context with poor social determinants of health, possibly being poorer, of lower education, discriminated against and living in an unhealthy neighbourhood and generally having fewer opportunities in life, morbidity and mortality rates increase and thus visits in occupational health services may increase. However, in this study frequent attendance to $\mathrm{OH}$ primary care was predictive of DP even when adjusted for confounding socioeconomic factors. This may be due to this study population consisting of employed persons, who may already be a healthier population than those who are not active in the workforce. However, the effect of social determinants of health could be seen in the gender differences in frequent attendance in the study, with women more often being frequent attenders to $\mathrm{OH}$ primary care than men. Whether this is due to different conditions, or different work characteristics, needs further study. Furthermore, it should be noted that the social and health inequities in Finland are among the lowest in Europe [31].

Table 3 Sociodemographic factors in 2013 associated with frequent attendance to OH primary care in 2014-2016 in multinomial logistic regression (adjusted for age)

\begin{tabular}{|c|c|c|c|c|c|c|}
\hline & \multicolumn{2}{|l|}{$1 \mathrm{yFA}$} & \multicolumn{2}{|l|}{$2 \mathrm{yFA}$} & \multicolumn{2}{|l|}{ pFA } \\
\hline & Female & Male & Female & Male & Female & Male \\
\hline & OR $(95 \% \mathrm{Cl})$ & & & & & \\
\hline \multicolumn{7}{|l|}{ Occupational class* } \\
\hline Manual & $1.58(1.39-1.79)$ & $1.92(1.73-2.14)$ & $2.37(1.86-3.01)$ & $2.85(2.24-3.62)$ & $3.02(2.05-4.44)$ & $2.93(1.97-4.34)$ \\
\hline Lower non-manual & $1.41(1.27-1.58)$ & $1.14(1.00-1.30)$ & $1.67(1.34-2.09)$ & $1.52(1.14-2.03)$ & $1.71(1.19-2.47)$ & $0.98(0.58-1.65)$ \\
\hline Entrepreneur & $0.5(0.36-0.69)$ & $0.73(0.59-0.92)$ & $0.25(0.10-0.62)$ & $0.39(0.20-0.76)$ & $0.28(0.07-1.16)$ & $0.22(0.05-0.92)$ \\
\hline Others & $1.08(0.93-1.27)$ & $1.10(0.94-1.28)$ & $0.77(0.54-1.11)$ & $1.20(0.85-1.71)$ & $1.03(0.58-1.82)$ & $1.06(0.59-1.91)$ \\
\hline \multicolumn{7}{|l|}{ Education** } \\
\hline Basic & $1.06(0.92-1.21)$ & $1.58(1.40-1.78)$ & $0.87(0.65-1.15)$ & $1.52(1.18-1.95)$ & $1.18(0.77-1.83)$ & $2.02(1.29-3.16)$ \\
\hline Intermediate & $1.34(1.24-1.45)$ & $1.76(1.62-1.93)$ & $1.53(1.33-1.77)$ & $2.00(1.67-2.40)$ & $2.07(1.63-2.62)$ & $2.79(1.99-3.90)$ \\
\hline Unemployment*** & $0.97(0.87-1.08)$ & $0.95(0.86-1.06)$ & $0.65(0.51-0.83)$ & $0.91(0.73-1.13)$ & $0.72(0.49-1.05)$ & $0.73(0.49-1.08)$ \\
\hline Living alone & $1.07(0.97-1.18)$ & $1.03(0.94-1.13)$ & $1.15(0.96-1.37)$ & $1.12(0.94-1.35)$ & $1.35(1.02-1.77)$ & $1.54(1.17-2.04)$ \\
\hline
\end{tabular}

Frequent attendance to $\mathrm{OH}$ primary care was defined as the top decile of attenders (frequent attender 10\%, FA10)

$1 \mathrm{yFA}=$ Patients that were in the top decile of attenders in one of the study years $(2014,2015$ or 2016)

$2 \mathrm{yFA}=$ Patients that were in the top decile in any two study years $(2014,2015$ or 2016)

pFA = Patients that were in the top decile in all three study years (2014, 2015 and 2016)

non-FA = Patients that were never in the top decile were considered as a reference group, non-frequent attenders

$\mathrm{OR}=$ odds ratio

$\mathrm{Cl}=$ confidence interval

${ }^{*}=$ reference upper non-manual, ${ }^{* *}=$ reference high education, ${ }^{* * *}=$ reference no unemployment in 2013

Confidence intervals $(\mathrm{Cl})$ estimated under normal distribution assumption 
Table 4 Predictive value of frequent attendance to $\mathrm{OH}$ primary care in 2014-2016 for disability pension in 2017-2018 when adjusted for age, sex, occupational class, educational level, unemployment, living alone, income and area of living

\begin{tabular}{|c|c|c|}
\hline & \multicolumn{2}{|l|}{ OR $(95 \% \mathrm{Cl})$} \\
\hline & Female & Male \\
\hline \multicolumn{3}{|c|}{ Permanent full-time DP } \\
\hline $1 \mathrm{yFA}$ & $2.9(1.77-4.75)$ & $4.01(2.78-5.78)$ \\
\hline $2 y F A$ & $7.96(4.54-13.95)$ & $2.31(1.10-4.83)$ \\
\hline $\mathrm{pFA}$ & $4.08(1.44-11.58)$ & $5.81(2.59-13.05)$ \\
\hline \multicolumn{3}{|l|}{ Any DP } \\
\hline $1 y F A$ & $3.29(2.59-4.17)$ & $3.66(2.90-4.6)$ \\
\hline $2 y F A$ & $6.19(4.52-8.49)$ & $2.48(1.56-3.92)$ \\
\hline pFA & $5.07(3.09-8.33)$ & $5.76(3.36-9.89)$ \\
\hline
\end{tabular}

Frequent attendance to $\mathrm{OH}$ primary care was defined as the top decile of attenders (frequent attender 10\%, FA10)

$1 \mathrm{yFA}=$ Patients that were in the top decile of attenders in one of the study years $(2014,2015$ or 2016)

2yFA = Patients that were in the top decile in any two study years $(2014,2015$ or 2016)

pFA = Patients that were in the top decile in all three study years $(2014,2015$ and 2016)

non-FA $=$ Patients that were never in the top decile were considered as a reference group, non-frequent attenders

$\mathrm{OR}=$ odds ratio

$\mathrm{Cl}=$ confidence interval

Having less vocational education and lack of professional education have been linked to frequent attendance to $\mathrm{OH}$ primary in GP setting $[32,33]$ and also to DP $[18,19]$. This finding was verified in this setting, with data consisting of the working population alone. Interestingly, intermediate education appeared to have a stronger association with frequent attendance to $\mathrm{OH}$ primary than basic education did. This could be associated with psychological and physical demands of their work, however this finding requires further examination. We have previously perceived an association with human health and social work activities, that could be linked educational level also [4].

Entrepreneurs and upper non-manual workers are less likely to be FA. Entrepreneurs pay for their OHS themselves, which might affect their service use. Entrepreneurs are entitled to compensation from the state for OHS, but nevertheless, only a minority of sole entrepreneurs organise OHS for themselves [34]. Entrepreneurs are also underrepresented in our data compared to the general population [35], which might affect the perceived association.

Non-manual work is less physically strenuous than manual work and the physical demands are lower. Thus, the previously perceived association with musculoskeletal disorders of the FAs [36] may be explained by their occupational class and the demands of their work. On the other hand, physically demanding working conditions and manual work are also linked to DPs [37]. A previous study found an association between frequent attendance to $\mathrm{OH}$ primary care and manufacturing industry and human health and social work activities [4]. That study could not control for the impact of occupational class, a gap that this study addresses. Manual and lower non-manual work is common in these industries, that are also often physically demanding. In our study lower manual work in particular was associated with FA, therefore it appears that patients working in manual professions might benefit from planned healthcare services when an illness affecting work ability arises.

In the GP setting, frequent attendance to $\mathrm{OH}$ primary care has been linked to unemployment [5, 9] and unemployment is also linked to DP risk [38]. In this setting of $\mathrm{OH}$ primary care, being unemployed in 2013 was not associated with frequent attendance to $\mathrm{OH}$ primary care in the following years. There might be several reasons behind this. It is possible that one might enter working life only briefly after unemployment periods and thus might not "have time" to become FA. On the other hand, one might underuse services or not use services provided by the employer in the fear of losing work. Interestingly, the data indicate that over the years some pFAs drifted towards longer unemployment periods. This was not visible among the non-FAs. Studies suggest that sickness absences are a risk for unemployment and job termination for temporary jobs [39] and this could be one explanation. Future studies are needed to study the patients that are lost to lollow-up in the OHS.

A previous study showed that frequent attendance is linked to work disability in the near future [17]. Previous studies have also shown a link with prolonged sickness absences [16, 40]. Also, low socioeconomic status has been linked to sickness absences for mental disorders in frequent users of OHS [15]. The current study examined disability pensions in the years following frequent attendance, taking into account the potential confounding effects of sociodemographic variables. These analyses suggest that frequent attendance is associated not only with permanent full-time DP but also any DP, despite the underlying sociodemographic factors (age, sex, occupational class, educational level, unemployment, living alone, disposable family income and area of living). The sociodemographic factors are rarely available in any medical records - thus they cannot be used in identifying disability risks although they are known the be linked to increased risk for work disability. Frequency of visits is, however, easily available through medical records and can be used to identify persons at risk of work disability risk. The results can be easily taken into practice and thus aid health service providers and physicians. This finding emphasizes the value of consultation frequency as an additional indicator for identifying disability risks. 
It should be noted, that other DP decisions than permanent full-time DP (i.e. fixed-term and partial solutions) are endpoints that reflect the realization of work disability but at the same time they are also supportive measures to help patients stay and return to working life. Fixed-term DP decisions are meant for the period necessary for recovery and only approximately half lead to permanent DP during a four-year follow-up [41]. Partial DPs allow for staying in the workforce and are particularly useful towards the end of the working career, when some work ability remains despite illnesses and disabilities. This often requires work modifications in the workplace which are agreed upon during $\mathrm{OH}$ negotiations [42], which are a supportive structure of the Finnish OHS. Identifying patients with work disability risks in all healthcare sectors and steering them to OHS to initiate support mechanisms at the workplace and in OHS is crucial.

OHS in Finland aim to prolong working careers and help maintain work ability. Sickness absence monitoring is most commonly used in identifying individuals at risk of work disability [43, 44]. This is, however, a rather late indicator and additional possibly earlier indicators would be welcome. Identifying persons at risk of DP who need additional support could work best through using several indicators. Currently persons with lowered work ability and risk of DP are identified at the physicians' office [45] and through a self-evaluation questionnaire [46]. Once identified, the multifaceted support mechanisms of OHS should be exploited to find solutions that restore work ability: $\mathrm{OH}$ negotiations to agree on necessary work modifications, educational training or vocational rehabilitation are just some measures that aim to prolong staying in the workforce. Instituting these measures earlier could support protecting work ability and cooperation between healthcare sectors.

This study provides new understanding of frequent attenders of $\mathrm{OH}$ primary care and a unique view on the working population. The studied population is large and represents the working population in Finland quite well, with patients from both rural and urban areas. There are slightly fewer municipal workers than in the general population and thus the manufacturing industry is accentuated. The study design, combining routine medical record data that are easily available with large register data is an emerging field of study providing important information. Registers in Finland are generally of good quality and have minimal numbers of missing data. The follow-up study design allows for a more complete understanding of the associations between sociodemographic factors and service use. Although $\mathrm{OH}$ primary care as such does not exist outside Finland, our results allow some generalisation to the working population also outside Finland, often treated by GPs. Patients that had no visits to $\mathrm{OH}$ primary care during the years were not included, since their data are not available in the medical record database. Despite the large cohort, the group of pFAs represents less than $1 \%$ of the whole study population (however containing 592 patients), which might lead to lacking statistical significance. It should also be noted, that patients that fall ill very rapidly, might end up on DP without frequent visits to $\mathrm{OH}$ primary care. Illnesses such as serious cancers and heart failures, could be an example. Due to the dynamic nature of the cohort, patients may be lost to follow-up if their employment ends. This is a limitation, but the large sample dilutes the effect. Furthermore,this study is limited by the inability to track the use of other healthcare services over the years. This should be studied in the future, as unemployment might steer service use to other sectors. Whether this affects disability risks should be examined.

\section{Conclusions}

Frequent attendance to $\mathrm{OH}$ primary care is associated with disability pensions despite underlying sociodemographic differences. These individuals should be identified by professionals treating working patients and rehabilitative needs and other measures necessary to help staying in the working life should be used early on. Consultation frequency is an additional measure that could be used alongside other measures in identifying patients in need of additional support.

\section{Abbreviations \\ Cl: Confidence interval; DP: Disability pension; FA: Frequent attender; FCP: Finnish Centre for Pensions; GP: General practice; $\mathrm{OH}$ : Occupational health; OHS: Occupational health services; OR: Odds ratios; pFA: Persistent frequent attender}

\section{Acknowledgements \\ The authors acknowledge the participation of all the individual patients who are part of this study.}

\section{Authors' contributions \\ The study was conceptualized by JU. The study design was planned by RS, $J U, M V, M S, A S, M K, S A$ and TR. Planning of data collection was done by RS, $J U, M V, M S, A S, M K, S A$ and TR. The design for data analysis design was done by RS, JU, MV, MS, AS, MK, SA and TR. MK analyzed the data. TR wrote the first draft and RS, JU, MV, MS, AS, MK, SA and TR contributed to the final version by revising and commenting on the draft. RS, JU, MV, MS, AS, MK, SA and TR approved the final version.}

\section{Funding}

This study was supported by the Finnish Work Environment Fund (TSR 117360) and by Valtion tutkimusrahoitus (9X057). The funders had no role in the design of the study nor collection, analysis, and interpretation of data or in writing the manuscript.

\section{Availability of data and materials}

The data supporting the findings are combined for the purposes of this study and are stored by Statistics Finland. Restrictions apply to the availability of these data, which were used under license for the current study, and so they are not publicly available. 


\section{Declarations}

\section{Ethics approval and consent to participate}

The ethics committee of Pirkanmaa Hospital District (ETL R16041) approved the study and the administrative permission was granted by the National Institute of Health and Welfare (THL/556/5.05.0O/2016). Based on Finnish legislation (Personal Data Act, Finland, 22.4.1999) individual consent is unnecessary since no individual could be identified due to the size of the study population.

\section{Consent for publication}

Not applicable.

\section{Competing interests}

The Authors declare that there is no conflict of interest.

\section{Author details}

${ }^{1}$ Tampere University, Faculty of Medicine and Health Technology, Tampere, Finland. ${ }^{2}$ Pihlajalinna Työterveys, Tampere, Finland. ${ }^{3}$ Department of Public Health Sciences, Karolinska Institutet, Stockholm, Sweden. ${ }^{4}$ Tampere University, New Social Research and Faculty of Social Sciences, Tampere, Finland. ${ }^{5}$ Finnish Institute of Occupational Health, Tampere, Finland. ${ }^{6} \mathrm{Clinic}$ of Occupational Medicine, Tampere University Hospital, Tampere, Finland.

\section{Received: 22 September 2020 Accepted: 28 September 2021} Published online: 12 October 2021

\section{References}

1. Smits FT, Brouwer HJ, ter Riet G, van Weert HC. Epidemiology of frequent attenders: a 3-year historic cohort study comparing attendance, morbidity and prescriptions of one-year and persistent frequent attenders. BMC Public Health. 2009;9(1). https://doi.org/10.1186/1471-2458-9-36

2. Rosella LC, Fitzpatrick T, Wodchis WP, Calzavara A, Manson H, Goel V. Highcost health care users in Ontario, Canada: demographic, socio-economic, and health status characteristics. BMC Health Serv Res. 2014;14(1):532. https://doi.org/10.1186/s12913-014-0532-2.

3. Smits FT, Brouwer HJ, Zwinderman AH, Mohrs J, Smeets HM, Bosmans JE, et al. Morbidity and doctor characteristics only partly explain the substantial healthcare expenditures of frequent attenders: a record linkage study between patient data and reimbursements data. BMC Fam Pract. 2013;14(1). https://doi.org/10.1186/1471-2296-14-138.

4. Reho T, Atkins S, Talola N, Sumanen M, Viljamaa M, Uitti J. Frequent attenders in occupational health primary care - a cross-sectional study. Scand J Public Health. 2018;47(1):28-36. https://doi.org/10.1177/140349481 8777436.

5. Vedsted $P$, Christensen MB. Frequent attenders in general practice care: a literature review with special reference to methodological considerations. Public Health. 2005;1 19(2):118-37. https://doi.org/10.1016/j.puhe.2004.03.007.

6. Hansagi H, Olsson M, Sjöberg S, Tomson Y, Göransson S. Frequent use of the hospital emergency department is indicative of high use of other health care services. Ann Emerg Med. 2001;37(6):561-7. https://doi.org/10.1 067/mem.2001.111762

7. Pymont C, Butterworth P. Longitudinal cohort study describing persistent frequent attenders in Australian primary healthcare. BMJ Open. 2015;5(10): e008975. https://doi.org/10.1136/bmjopen-2015-008975.

8. Carney TA, Guy S, Jeffrey G. Frequent attenders in general practice: a retrospective 20-year follow-up study. Br J Gen Pract. 2001;51(468):567-9.

9. Gill D, Sharpe M. Frequent consulters in general practice: a systematic review of studies of prevalence, associations and outcome. J Psychosom Res. 1999;47(2):115-30. https://doi.org/10.1016/S0022-3999(98)00118-4.

10. Droomers M, Westert GP. Do lower socioeconomic groups use more health services, because they suffer from more illnesses? Eur J Pub Health. 2004; 14(3):311-3. https://doi.org/10.1093/eurpub/14.3.311.

11. Kersnik J, Scvab I, Vegnuti M. Frequent attenders in general practice: quality of life, patient satisfaction, use of medical services and GP characteristics. Scand J Prim Health Care. 2001;19(3):174-7. https://doi.org/10.1080/0281343 01316982405

12. Reid S, Wessely S, Crayford T, Hotopf M. Frequent attenders with medically unexplained symptoms: service use and costs in secondary care. $\mathrm{Br} J$ Psychiatry. 2002;180(3):248-53. https://doi.org/10.1192/bjp.180.3.248.
13. Vedsted $\mathrm{P}$, Olesen F. Social environment and frequent attendance in Danish general practice. Br J Gen Pract. 2005;55(516):510-5.

14. Scaife B, Gill P, Heywood P, Neal R. Socio-economic characteristics of adult frequent attenders in general practice: secondary analysis of data. Fam Pract. 2000;17(4):298-304. https://doi.org/10.1093/fampra/17.4.298.

15. Harkko J, Sumanen H, Pietiläinen $\mathrm{O}$, Piha K, Mänty M, Lallukka T, et al. Socioeconomic differences in occupational health service utilization and sickness absence due to mental disorders: a register-based retrospective cohort study. Int J Environ Res Public Health. 2020;17(6):1-13. https://doi. org/10.3390/ijerph17062064.

16. Bergh H, Baigi A, Månsson J, Mattsson B, Marklund B. Predictive factors for long-term sick leave and disability pension among frequent and normal attenders in primary health care over 5 years. Public Health. 2007;121(1):2533. https://doi.org/10.1016/j.puhe.2006.08.018.

17. Reho TTM, Atkins SA, Talola N, Sumanen MPT, Viljamaa M, Uitti J. Frequent attenders at risk of disability pension: a longitudinal study combining routine and register data. Scand J Public Health. 2020;48(2):181-9. https:// doi.org/10.1177/1403494819838663.

18. Krokstad S, Johnsen R, Westin S. Social determinants of disability pension: a 10-year follow-up of 62000 people in a Norwegian county population. Int J Epidemiol. 2002;31(6):1183-91. https://doi.org/10.1093/ije/31.6.1183.

19. Bruusgaard D, Smeby L, Claussen B. Education and disability pension: a stronger association than previously found. Scand J Public Health. 2010; 38(7):686-90. https://doi.org/10.1177/1403494810378916.

20. Leinonen T, Martikainen P, Lahelma E. Interrelationships between education, occupational social class, and income as determinants of disability retirement. Scand J Public Health. 2012;40(2):157-66. https://doi.org/10.11 77/1403494811435492.

21. Marmot M. Social determinants of health inequalities. Lancet. 2005; 365(9464):1099-104. https://doi.org/10.1016/S0140-6736(05)71146-6.

22. Lappalainen K, Aminoff M, Hakulinen H, Hirvonen M, Räsänen K, Sauni R, et al. Työterveyshuolto Suomessa vuonna 2015 [occupational healthcare in Finland 2015 report] (in Finnish with english summary). Helsinki: Työterveyslaitos; 2016.

23. Ikonen $A$, Räsänen $K$, Manninen $P$, Rautio $M$, Husman $P$, Ojajärvi $A$, et al. Use of health services by Finnish employees in regard to health-related factors: the population-based health 2000 study. Int Arch Occup Environ Health. 2013:86(4):451-62. https://doi.org/10.1007/s00420-012-0778-0.

24. Li CY, Sung FC. A review of the healthy worker effect in occupational epidemiology. Occup Med (Chic III). 1999;49(4):225-9. https://doi.org/10.1 093/occmed/49.4.225

25. Koskinen S, Lundqvist A, Ristiluoma N, eds. Terveys, toimintakyky ja hyvinvointi Suomessa 2011 [Health, functional capacity and welfare in Finland in 2011] (In Finnish with English summary). Helsinki; 2012.

26. Kauppinen T, Mattila-Holappa P, Perkiö-Mäkelä M, Saalo A, Toikkanen J, Tuomivaara S, et al. Työ ja Terveys suomessa 2012 Seurantatietoa työoloista ja työhyvinvoinnista (In Finnish with English summary). Helsinki: Työterveyslaitos; 2013

27. Statistics Finland, FOLK-database, Basic data - data description. https://taika.stat. fi/en/aineistokuvaus.html\#!?dataid=FOLK_19872019_jua_perus20_002.xml.

28. Forssas E, Manderbacka K, Arffman M, Keskimäki I. Socio-economic predictors of mortality among diabetic people. Eur J Pub Health. 2012;22(3): 305-10. https://doi.org/10.1093/eurpub/ckr044.

29. Lahtinen $H$, Sirniö O, Martikainen P. Social class and the risk of unemployment: Trends, gender differences and the contribution of education. Acta Sociol (United Kingdom). 2020;63:303-21.

30. WHO. Social determinants of health. https://www.who.int/teams/socialdeterminants-of-health. Accessed 16 Aug 2021.

31. Marmot M, Bell R. Fair society, healthy lives. Public Health. 2012;126:S4-S10. https://doi.org/10.1016/j.puhe.2012.05.014.

32. Jyväsjärvi S, Keinänen-Kiukaanniemi S, Väisänen E, Larivaara P, Kivelä SL. Frequent attenders in a Finnish health Centre: morbidity and reasons for encounter. Scand J Prim Health Care. 1998;16(3):141-8. https://doi.org/10.1 080/028134398750003089.

33. Karlsson $\mathrm{H}$, Lehtinen $\mathrm{V}$, Joukamaa M. Frequent attenders of Finnish public primary health-care - sociodemographic characteristics and physical morbidity. Fam Pract. 1994;11(4):424-30. https://doi.org/10.1093/fa mpra/11.4.424.

34. Palmgren H, Kaleva S, Savinainen M, Rajala K. Yrittäjien ja pienten yritysten työterveyshuolto Suomessa 2013-2014 (In Finnish with English summary). Helsinki: Työterveyslaitos; 2015. 
35. Sutela H, Pärnänen A. Yrittäjät Suomessa 2017 (Entrepreneurs in Finland) [ln Finnish]. Helsinki: Tilastokeskus; 2018.

36. Reho T, Atkins S, Talola N, Sumanen M, Viljamaa M, Uitti J. Comparing occasional and persistent frequent attenders in occupational health primary care - a longitudinal study. BMC Public Health. 2018;18(1):1-9. https://doi. org/10.1186/s12889-018-6217-8

37. Polvinen A, Gould R, Lahelma E, Martikainen P. Socioeconomic differences in disability retirement in Finland: the contribution of ill-health, health behaviours and working conditions. Scand J Public Health. 2013;41(5):470-8. https://doi.org/10.1177/1403494813482400.

38. Gustafsson K, Aronsson G, Marklund S, Wikman A, Floderus B. Peripheral labour market position and risk of disability pension: a prospective population-based study. BMJ Open. 2014;4(8):e005230. https://doi.org/1 0.1136/bmjopen-2014-005230.

39. Virtanen M, Kivimäki M, Vahtera J, Elovainio M, Sund R, Virtanen P, et al. Sickness absence as a risk factor for job termination, unemployment, and disability pension among temporary and permanent employees. Occup Env Med. 2006;63(3):212-7. https://doi.org/10.1136/oem.2005.020297.

40. Reho T, Atkins S, Talola N, Sumanen M, Viljamaa M, Uitti J. Occasional and persistent frequent attenders and sickness absences in occupational health primary care: a longitudinal study in Finland. BMJ Open. 2019;9(2):e024980. https://doi.org/10.1136/bmjopen-2018-024980

41. Laaksonen M, Rantala J, Järnefelt N, Kannisto J. Työkyvyttömyyden vuoksi menetetty työura (working careers lost due to disability) [in Finnish with English summary]. Helsinki: Finnish Centre for Pensions; 2016.

42. Lappalainen L, Liira J, Lamminpää A, Rokkanen T. Work disability negotiations: supervisors' view of work disability and collaboration with occupational health services. Disabil Rehabil. 2019;41(17):2015-25. https:// doi.org/10.1080/09638288.2018.1455112.

43. Salonen L, Blomgren J, Laaksonen M, Niemelä M. Sickness absence as a predictor of disability retirement in different occupational classes: a registerbased study of a working-age cohort in Finland in 2007-2014. BMJ Open. 2018;8(5):1-8. https://doi.org/10.1136/bmjopen-2017-020491.

44. Kivimäki M, Forma P, Wikström J, Halmeenmäki T, Pentti J, Elovainio M, et al. Sickness absence as a risk marker of future disability pension: the 10-town study. J Epidemiol Community Heal. 2004;58(8):710-1. https://doi.org/10.113 6/jech.2003.015842.

45. Atkins S, Reho T, Talola N, Sumanen M, Viljamaa M, Uitti J. Improved recording of work relatedness during patient consultations in occupational primary health care: a cluster randomized controlled trial using routine data. Trials. 2020;21(1):1-8. https://doi.org/10.1186/s13063-020-4168-8.

46. Pihlajamäki M, Uitti J, Arola H, Korhonen M, Nummi T, Taimela S. Selfreported health problems in a health risk appraisal predict permanent work disability: a prospective cohort study of 22,023 employees from different sectors in Finland with up to 6-year follow-up. Int Arch Occup Environ Health. 2020;93(4):445-56. https://doi.org/10.1007/s00420-019-01497-2.

\section{Publisher's Note}

Springer Nature remains neutral with regard to jurisdictional claims in published maps and institutional affiliations.

Ready to submit your research? Choose BMC and benefit from:

- fast, convenient online submission

- thorough peer review by experienced researchers in your field

- rapid publication on acceptance

- support for research data, including large and complex data types

- gold Open Access which fosters wider collaboration and increased citations

- maximum visibility for your research: over $100 \mathrm{M}$ website views per year

At $\mathrm{BMC}$, research is always in progress.

Learn more biomedcentral.com/submissions 